\title{
Pattern of X-Ray Findings at 563 Nigeria Airforce Hospital, Jos
}

\author{
Salaam AJ, ${ }^{1}$ Danjem Sm, ${ }^{1}$ Salaam AA,,${ }^{2}$ Tanko AA,,${ }^{3}$ Oyebola EB, ${ }^{3}$ Ollawa CU, ${ }^{3}$ Sekat NB, ${ }^{1}$ Angba HA, ${ }^{1}$ Igoh \\ EO, ${ }^{1}$ Gabkwet AE, ${ }^{1}$ Kolade-Yunusa HO. ${ }^{4}$ \\ ${ }^{1}$ Department of Radiology, Jos University Teaching Hospital \\ ${ }^{2}$ Department of Family Medicine, Jos University Teaching Hospital \\ ${ }^{3} 563$ Nigeria Airforce Hospital, Jos \\ ${ }^{4}$ Department of Radiology, University of Abuja Teaching Hospital
}

*Corresponding Author: Department of Radiology, Jos University Teaching Hospital.e-mail: adeku2s@gmail.com

\begin{abstract} Date Published: 03/04/2020

This study aimed at investigating various conditions and findings on X-rays. X-ray is an electromagnetic wave that is used in evaluating patients with different disease condition. X-ray of patients that presented to the radiology department between June 2015 and June 2016 were evaluated for the study. Demographic data, indications and findings were evaluated. The result shows, that there was a total of 368 subjects. Females $(50.5 \%)$ were more than males in the study. Hypertension constituted the predominant indication for X-ray, this accounted for 87 subjects $(23.6 \%)$, followed by medical fitness, 74 subjects (20.1\%). Over $50 \%$ of the findings were normal, followed by lumbar spondylosis and then hypertension. In conclusion, more than half of the participants had normal findings. Lumbar spondylosis and hypertension were the most frequent indications and findings.
\end{abstract}

Article Information:

Date Submitted: 01/12/2019. Date Accepted: $17 / 02 / 2020$

Keywords:Findings, Hospital, Indications, X-ray

\section{INTRODUCTION}

$\mathrm{X}$ -ray can be defined as an electromagnetic wave of high energy and very short wavelength, which is able to pass through many materials opaque to light. ${ }^{1} \mathrm{X}$ rays were discovered in Europe on $8^{\text {th }}$ November, 1895 by a German physicist, Wilhelm Comrad Roentgen in his laboratory at polytechnic institute Zurich, Germany. The end product of the radiographic process in the production of a "dark film" radiograph of high diagnostic value. Xray films exposed to transmitted $\mathrm{x}$-radiation from anatomical parts under examination has imprinted on them latent images of structures traversed. This latent image is made visible by chemical or digital processing. Several applications of $\mathrm{x}$-rays include engineering, archeology, industries, airport-security, astronomy, biotechnology, and medicine. ${ }^{2}$ In medicine, x-rays are used for treatment of malignant growths and for diagnosis of various disease conditions such as Osteoarthritis, Hypertension, Pneumonia, fractures, dislocation etc. ${ }^{3}$ The World Health Organization's (WHO) International Agency for Research on Cancer and the US government have classified x-rays as carcinogens. Bremer et al., estimated that $0.4 \%$ of current 
cancers in the US are due to CT scan performed in the past and may increase to as high as $1.5 \%$ to $2.0 \%$ with 2007 rate of CT or x-ray usage. Military hospitals are instituted to cater for injured soldiers, military personnel and their dependents. The primary clientele of 563 NAF Hospital, Jos include the military schools- Air Force Military School (AFMs) and Air Force Girls Comprehensive School (AFGCS), residents within the barrack community as well as the retirees that are resident within the metropolis. This study therefore presents the pattern of x-ray findings at 563 NAF hospital Jos between June 2015 to June 2016 in relation to age groups, sex distribution and the medical conditions.

\section{Aim and Objectives of the Study}

The main aim of this study was to assess the pattern of disease conditions in relation to the ages and sexes of the respondents in NAF Hospital, Jos.

\section{Objectives}

To assess the disease distribution by age, sex and type of medical conditions seen at 563 NAF Hospital Jos.To determine the common medical conditions seen in the center and to contribute research-based relevant data that will assist in rational decision making.

\section{Significance of the study}

Number of patients accessing $x$-ray services in military hospital seems to be on the rise, notwithstanding the dwindling allocation. Data on predominant disease conditions generating requests for $\mathrm{x}$-ray from the physicians, age and sex of the patients is currently unavailable in this center. Results from this study will provide relevant information for effective allocation of scarce resources as well as policy formulation and decision making by the hospital.

\section{Scope of the study}

Statistical analysis of data obtained from x-ray request forms and radiologist report findings between June 2015 and June 2016, form the scope of the study.

\section{MATERIALS AND METHODS}

\section{Study area}

The study was carried out in NAFH, a secondary healthcare facility located in the city of Jos, Jos South LGA of Plateau State in North-Central Nigeria. Study Design: This was a cross-sectional study of all patients that accessed health care at 563 NAFH and had x-ray services.

\section{Data Collection}

Age and sex of the patients that had x-ray investigation were obtained from the request forms. Frequency of all medical indications for x-ray were collated. Results of the x-ray findings were also obtained from the radiologist reports at 563 NAF Hospital Jos.

\section{Inclusion Criteria}

All patients that had $\mathrm{x}$-ray investigations.

\section{Data Analysis}

Data were analyzed using SPSS version 23,results obtained were reported in form of frequency tables and bar charts.

\section{RESULTS}

\section{Table 1: Age Distribution of the Respondents}

\begin{tabular}{lll}
\hline Age & Frequency & Percent \\
\hline$<10$ yrs & 14 & 3.8 \\
$10-19$ yrs & 60 & 16.3 \\
$20-29 y r s$ & 41 & 11.1 \\
$30-39$ yrs & 43 & 11.7 \\
$40-49$ yrs & 104 & 28.3 \\
$50-59$ yrs & 49 & 13.3 \\
$>50 y r s$ & 57 & 15.5 \\
$\mathrm{~N}$ & 368 & 100 \\
\hline
\end{tabular}

Respondents within the $40-49$ years age group had the highest frequency while those within the $<10$ yrs age group had the least frequency

Table 2: Sex Distribution of Respondents

\begin{tabular}{lcc}
\hline Sex & Frequency & Percent \\
Female & 186 & 50.5 \\
Male & 182 & 49.5 \\
\hline $\mathrm{n}$ & 368 & 100 \\
\hline
\end{tabular}

With regards to gender, there were more females than males in the distribution of $\mathrm{x}$-ray requests in this hospital.(Table 2)

The most common indication for x-ray was hypertension, while the least common were pre-surgery evaluation and retroviral cases. 
Table 3: Distribution of Indications for X- Ray.

\begin{tabular}{lll}
\hline Medical Indications & Frequency & Percent \\
\hline Medical fitness & 74 & 20.1 \\
Chest pain & 24 & 6.5 \\
Suspected fracture & 22 & 6.0 \\
Lower back pain & 56 & 15.2 \\
Hypertension & 87 & 23.6 \\
Post trauma & 4 & 1.1 \\
Chest infection & 50 & 13.6 \\
Joint pain & 7 & 1.9 \\
Neck pain & 14 & 3.8 \\
Preurgery evaluation & 2 & 0.5 \\
Post obstructive airway disease & 21 & 5.7 \\
Heart failure & 5 & 1.4 \\
Retroviral disease & 2 & 0.5 \\
\hline N & $\mathbf{3 6 8}$ & $\mathbf{1 0 0}$ \\
\hline
\end{tabular}

Table 4: Distribution of Conditions (Result) Based on their X Ray reports

\begin{tabular}{lll}
\hline Result & Frequency & Percent \\
\hline Normal study & 204 & 55.4 \\
Lumbar spondylosis & 39 & 10.6 \\
Hypertensive heart disease & 17 & 4.6 \\
Hypertension & 38 & 10.3 \\
Muscle spasm & 30 & 8.2 \\
Chest infection & 17 & 4.6 \\
Rib fracture & 2 & 0.5 \\
Cervical spondylosis & 10 & 2.7 \\
Broncho pneumonia & 3 & 0.8 \\
Constipation & 1 & 0.3 \\
Congenital anomaly of the rib & 1 & 0.3 \\
Malignant body lesion & 1 & 0.3 \\
Osteoarthritis & 1 & 0.3 \\
Avascular necrosis of femoral & 1 & 0.3 \\
head & & \\
Mandibular fracture & 1 & 0.3 \\
Soft tissue injury & 2 & 0.5 \\
\hline N & $\mathbf{3 6 8}$ & 100 \\
\hline
\end{tabular}

The results of the $\mathrm{x}$-ray revealed that majority were normal study, followed by lumbar spondylosis. Indications with the least frequency include mandibular fracture, avascular necrosis and malignant body lesion.

\section{DISCUSSION}

From the results, the respondents between ages 40-49 constituted the majority of respondents in which x-ray was indicated. This could be due to increase in disease conditions with onset within this age distribution. Conditions like hypertension and lower back pain, which in this study are the first and third most common indications, have their age of onset from 40years and above. ${ }^{5,6}$ In Nigeria, a study done by Ernest et al showed an increased prevalence of hypertension with advancing age. $^{9}$

There were more females than males in our study. This is in keeping with the study done by Lahelma et al., in Finland. ${ }^{7}$ Their study produced evidence that the magnitude of gender difference in ill-health was relatively small. Also, Ashley et al., in Canada, confirmed that women have greater health seeking behavior than men for both physical and mental health concerns. This study also shows that out of the 368 respondents, 204(58\%) had a normal study report which is the highest frequency. This could be due to the higher pre-school and routine medical examinations requests. Adeko et al., in their study done in Nigeria found that $95.2 \%$ of employees in the center had normal chest radiographic reports during a pre-employment examination. ${ }^{11}$ Some medical conditions may show normal plain radiographic findings at some stages of the disease; this may also have played out in our study.

Literature indicates that spondylosis has been used in several contexts, and often synonymously with arthrosis, spondylitis and osteoarthritis. It has also been considered as the hypertrophic response of adjacent vertebral bone to disc degeneration. ${ }^{12,13}$ Lumbar spondylosis was reported in $39(10.6 \%)$ and it is seen to affect respondents within the age distribution of 40years and above. Studies in the United States recognized that more than $80 \%$ of individuals older than 40 years have lumbar spondylosis. ${ }^{6}$ Large studies of osteoarthritis have long recognized the aging process to be the strongest risk factor for bony degeneration, particularly within the spine. ${ }^{12}$ However, there is no statistically significant association between the age and $x$-ray result. The occupation of the studied population could also contribute to the findings of lumbar spondylosis. Retrospective studies cite Body Mass Index (BMI), incident back trauma, daily spine loading (twisting, 
lifting, bending, and sustained non-neutral postures), and whole body vibration (such as vehicular driving) to be factors which increase both the likelihood and severity of spondylosis. ${ }^{14,15}$

In this study, hypertension constituted the most frequent indication for x-ray request, and it accounted for the second highest medical condition on $\mathrm{x}$-ray report. This could be related to the age of the respondents where most of the respondents fall within the higher age bracket in which hypertension is most prevalent. ${ }^{5}$ The need to assess target organ damage which is important in the evaluation of a hypertensive patient, as it provides important information on the severity of the hypertension and the cardiovascular risk assessment, ${ }^{6}$ could explain why the request for radiographs for respondents with hypertension is high. However, hypertension guidelines do not recommend chest radiographs in the routine evaluation of hypertensive patients.

Muscle spasm was also common, accounting for 30 $(8.2 \%)$. This could be occupation related knowing that most of the respondents were military personnel involved with much physical activities. Chest infections were among the most common infections encountered in out-patient and in-patient clinical care here; chest infection accounted for $4.6 \%$ of all the $\mathrm{X}$-rays done. In this study, Hypertensive heart disease accounted for $4.6 \%$. Ekpe et al., found that Hypertensive heart disease is the predominant acquired heart disease, which is not surprising as it is the reflection of the prevalence of systemic hypertension in Nigeria. ${ }^{18}$ According to WHO's Global status report on Non-communicable diseases 2010, the WHO African region, within which Nigeria is located, has the highest prevalence of hypertension among adults, estimated at $45 \%{ }^{17}$

Cervical spondylosis is a chronic degenerative condition of the cervical spine, and it accounted for $2.7 \%$ in our study, which is seen more in the middle aged than the elderly. This is in keeping with the study done by Wang et al., which shows a decreasing proportion of cervical spondylosis with aging in the elderly, while the proportion of cervical spondylosis increases with aging in the young and the adult population. ${ }^{19}$

\section{CONCLUSION}

There were more normal findings. This was followed by lumbar spondylosis and hypertension respectively.

\section{Conflict of interest}

None declared.

\section{REFERENCE}

1. F van Gelderen. A Brief History of Radiology Springer. 2004, Chapter 26, Pg 597-602

2. Bushberg JT, Seibert JA, Leidholdt EM, Boone JM. Film processing In: Essential Physics of Medical Imaging. $2^{\text {nd }}$ Edition, Philadelphia: Lippincott Williams \& Wilkins, 2002. Pg175-177

3. X-rays Dangers, Side Effects, Uses and Pregnancy Safety. www.medicinet.com[cited 2018 November 12].

4. Brenner DJ, Hall EJ. Computed tomography-An increasing source of radiation exposure. N Engl J Med 2007; 357:22772284.

5. Chawla J. Low back pain and sciatica. Medscape. [online] Aug 22, 2018 [Accessed 2019 Oct 21].Available at: https://emedicine.medscape.com/article/1144130overview

6. Bruce MB. Lumbar spondylosis. Medscape. [online] Sep 25, 2018 [Accessed 2019 Oct 21]. Available at: https://emedicine.medscape.com/article/249036-overview

7. Lahelma E, Martikain P, Rahkonen O, Silventoinen KJ. Gender differences in ill-health in Finland: Patterns, magnitude and change. Soc SciMed 1999; 48: 7-19.

8. Ashley ET, Yvonne A, Baukje-Baukje M, William H, Walter PW, Kriss A. The influence of gender and other patient characteristics on health care-seeking behavior: A QUALICOPC Study. BMC Family Practice 2016; 17:38doi10.1186/s12875-016-0440-0.

9. Ernest NA, Innocent CO, Anul NC, OnyebuchukwuDE. Hypertension and its socioeconomic factors in a market population in Akwa, Nigeria. AJMSM 2017;5(3): 40-48.

10. World Health Organization- International Society for Hypertension guidelines for the management of hypertension. J Hypertens 1999;17:151-183

11. Adeko OO, Ariba AJ, Olatunji AA, Toyobo OO. Routine chest radiograph in pre-employment medical examination for healthcare workers: Time for a review of the protocol. Niger Postgrad Med J 2017;24:93-6

12. Middleton K, Fish DE. Lumbarspondylosis: Clinical presentation and treatment approaches. Curr Rec Musculoskelet Med 2009; 2:94

13. Muraki S, Oka H, Akune T, Mabuchi A, En-yo Y, Yoshida M et al. Prevalence of radiographic lumbar spondylosis and its association with low back pain in elderly subjects of 
population-based cohorts: the ROAD study. Ann Rhem Dis. 2009;68(9): 1401

14. O'Neill TW, McCloskey EV, Kanis JA, Bhalla AK, Reeve J, Reid DM et al.The distribution, determinants and clinical correlates of vertebral osteophytosis: A population based survey. J Rheumatol. 1999; 26(4):842-8.

15. Videman T, Battié MC.The influence of occupation on lumbar degeneration. Spine 1999; 24(11):1164-8.

16. Buckwalter JA, Saltzman C, Brown T. The impact of osteoarthritis: Implications for research. Clin Orthop Relat Res. 2004; (427 Suppl):S6-15.

17. World Health Organization Bulletin 2013;91:242 243. Available from http://dx.doi.org/10.2471/BLT.13.020413. [cited 2018 January 3]

18. Ekpe EE, Ikpe MC, Umoh I. Echocardiographic pattern of acquired heart diseases in Nigeria. Niger Med J 2015;56:253-7.

19. Wang C, Tian F, Zhou Y, He W, Cai Z. The incidence of cervical spondylosis decreases with aging in the elderly, and increases with aging in the young and adult population: A hospital based clinical analysis. Clin Interv Aging 2016; 11:47-53. 